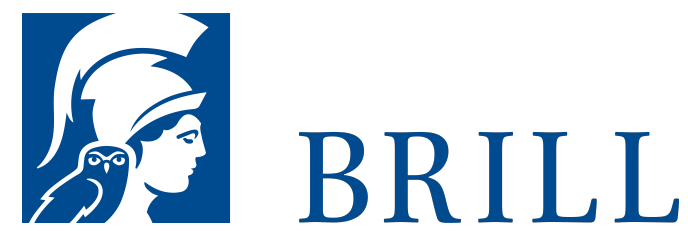

\title{
Kunst, Fiktion und Moral
}

Die Relevanz des moralischen Werts eines Kunstwerkes

Author: Lisa Katharin Schmalzried

Sind fiktionale Werke und Kunstwerke sinnvoll moralisch bewertbar? Und wenn ja, beeinflusst der moralische Wert eines Werkes dessen Wert, als Kunstwerk betrachtet, und wie beeinflusst er diesen? Als Antwort auf die erste Frage werden zwei Möglichkeiten einer sinnvollen moralischen Bewertung aufgezeigt. Zum einen ist ein Werk anhand der in ihm ausgedrückten moralischen Haltung(en) moralisch bewertbar und zum anderen anhand seines moralischen Potenzials. Eine moralische Haltung ist eine Positionierung hinsichtlich eines moralisch relevanten Sachverhalts. Ein moralisches Potenzial bezeichnet die Fähigkeit, moralisch relevantes Wissen zu vermitteln. Der moralische Wert eines Werkes kann dessen Wert, als Kunstwerk betrachtet, beeinflussen und zwar auf kontextualistische Art und Weise: Ein positiver moralischer Wert, ebenso wie ein moralisches Defizit, kann sich einmal positiv, ein andermal negativ auf den Gesamtwert auswirken. Hierfür wird auf Basis einer pluralistischen Werttheorie für Kunstwerke argumentiert, wonach unterschiedliche Bewertungsmaßstäbe angemessen für die Kunstkritik sind. Der Gesamtwert eines Werkes ergibt sich aus den Bewertungen auf Basis dieser einzelnen Kriterien.

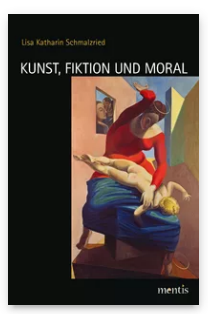

Pages: 389

Seiten

Language:

German

Subjects:

General, Philosophy

Publisher: Brill | mentis

E-Book (PDF)

Released online:

o1 Mar 2014

ISBN: 978-3-

$89785^{-985-2}$

List price

Paperback

Publication date: o1 Mar 2014 ISBN: $978-3^{-}$ 89785-841-1

List price 
For more information see brill.com

Order information: Order online at brill.com +44330 333 0049 | customerservices@brill.com Submission information: brill.com/authors

Titles published by Brill | Fink, Brill | mentis or Brill | Schöningh: +49(o)715413279216| brill@brocom.de 